\title{
UN MARCO PARA EL ESTUDIO DE LA INFRACCION URBANISTICA
}

71.343 .35

\author{
por \\ Vicente Boix Reig \\ Secretario de primera categoría de Administración local
}

SUMARIO: I. LA CAUSA DE LA INFRACCION URBANISTICA: 1. LA CUESTIÓN PREVIA PENAL. 2. ENFOQUES PRIVATISTAS. 3. ENFOQUES PUBLICISTAS: A) Principios esenciales: a) Principio de la legalidad urbanística. b) Principio de la congruencia urbanística. B) Principios subsidiarios: a) Principio de la interpretación discrecional. b) Principio de la variabilidad urbanística.-II. EL CONTENIDO DE LA INFRACCION URBANISTICA: 1. LOS BIENES JURIDICO-URBANISTICOS Y SU DEFENSA. 2. EL DERECHO OBJETIVO Y EL DERECHO SUBJETIVO URBANfSTICOS. 3. BIEN JURIDICO-URBANFSTICO E INSTITUCIONES URBANISTICAS.-III UN METODO PARA EL ESTUDIO DE LA INFRACCION URBANISTICA: 1. INSTITUCIONES URBANÍSTICAS Y TÉCNICAS REPRESIVAS. 2. MÉTODOS PARA EL ESTUDIO DE LAS INSTITUCIONES URBANf́ticas: A) Método dogmático. B) Método analitico: a) Idea general. b) Caracteres. c) Límites.IV. CONCLUSIONES.

\section{LA CAUSA DE LA INFRACCION URBANISTICA}

Toda actuación ilícita en materia urbanística tiene su peculiar justificación. El orden jurídico-urbanístico se suele vulnerar por alguna de las siguientes razones: 
- Por comodidad o por ignorancia del infractor.

- Por ignorancia o por negligencia del administrador urbanístico.

- Por un interés material de aquél o de éste, más o menos evaluable económicamente.

Cualesquiera de estas razones llevará a una situación antijurídica, cuyo tratamiento se acomete en nuestro Derecho por vía penal o por vía administrativa; y dentro de ésta, vamos a ver cómo la causa de la infracción ha sido contemplada en una primera época por la Jurisprudencia, con mentalidad privada, aunque pulatinamente se ha ido decantando hacia enfoques cada vez más publicistas.

\section{La CUESTIÓN PREVIa PENAL}

En ocasiones, el ilícito urbanístico se encuentra tipificado por la legislación penal. Corresponde entonces a esta especial rama del Derecho su comprensión y su tratamiento.

Aquí debemos limitarnos a la infracción propiamente administrativa, que es aquella cuya causa o no es considerada por el legislador con entidad suficiente como para ser reprimida por vía criminal, o no se estima que los hechos urbanísticos que determina estén realizados con dolosa intencionalidad en sus sujetos o hayan producido grave daño en valores jurídicos relevantes. La delimitación del ilícito penal y del ilícito administrativo en materia urbanística no es, sin embargo, clara, ya que arrastra tras de sí la misma imprecisión de contornos que rodea todo intento diferenciador de la falta penal y de la infracción administrativa.

Baste aquí por resaltar que algunas sentencias (1) resaltan con acierto la influencia que el Derecho penal debe ejercer en todo intento de calificación del ilícito urbanístico. Así, la sentencia de

(1) La sentencia del Tribunal Supremo de 17 de noviembre de 1975 dice: a... autonomía al Derecho administrativo sancionador con respecto al penal..., pero común injerencia en bienes particulares afectados por penas y sanciones, lo que en punto a garantías subjetivas se traduce en una coMUNIDAD DE PRINCIPIOS RECTORES... que inducen a aplicar al ámbito de la sanción administrativa los esenciales y genéricos principios de garantía penal». 
Audiencia confirmada por la del Tribunal Supremo de 21 de junio de 1975, que dice:

«Los principios fundamentales de la infracción y de la legalidad de la pena operan con atenuado rigor cuando se trata de infracciones administrativas y no de contravenciones de carácter penal; TAL CRITERIO DE FLEXIBILIDAD TIENE COMO LIMITES INSALVABLES la necesidad de que el acto o la omisión castigadas se hallen claramente definidos como falta administrativa..., DEBIENDO RECHAZARSE LA INTERPRETACION EXTENSIVA O ANALOGICA DE LA NORMA...».

La causa del ilícito urbanístico será así contemplada, en algunos casos, a través de los elementos definidores de los diferentes tipos delictivos. En otro momento se intentará clarificar el marco que corresponda a figuras dudosas de difícil encuadramiento, tanto en el marco criminal como en el administrativo. La causa que vamos a intentar captar ahora es la que se manifiesta en aquellos ilícitos urbanísticos que por su entidad son asignados por el legislador al simple tratamiento administrativo.

\section{ENFOQUES PRIVATISTAS}

Una antigua y todavía importante línea de pensamiento adopta modelos propios del Derecho privado: se considera que los valores urbanísticos son algo negociable entre la Administración y el administrado; se intenta potenciar el valor del precedente, sea o no legal, para montar la aplicación de la doctrina de la igualdad de trato; se introduce incluso el valor de la costumbre como fuente normativa de aplicación paralela. $Y$ en definitiva se fundamenta el ilícito urbanístico incluso en la falta de respeto al acuerdo de las voluntades pública y privada.

Planteamientos de este tipo encontraban incluso apoyo en alguna extraña figura legal, como la del artículo 228 de la antigua Ley del Suelo - suprimido en la reforma de 1975—, según el cual no se ejecutaban en sus propios términos las sentencias firmes, si a juicio de la respectiva Comisión Provincial de Urbanismo se imponía conservar la obra realizada por motivos de interés público. Extraña figura, porque si la fiscalización del respeto al interés público prevalente corresponde a los Tribunales respecto 
a la Administración, con este precepto se invertían los términos y era la Administración la que controlaba el juicio fiscalizador de los Tribunales.

Los enfoques concretos que se derivaban de esta orientación privatista eran, $\mathrm{y}$ en parte aún siguen siendo, los siguientes:

a) Los defensores del hecho consumado encontraban apoyo en una reducida pero peligrosa colección de sentencias (2) que parten de la comprensión privada, tanto de los derechos urbanísticos como de la actuación administrativa que se desarrolla para su control. Así, la sentencia del Tribunal Supremo de 17 de junio de 1961, que dice:

(2) Sentencia de Audiencia confirmada por la del Tribunal Supremo de 18 de diciembre de 1968, que dice: a... en Derecho... surgen ocasiones en las que no es posible desconocer la realidad conformada por acontecimientos sucedidos en el devenir del tiempo y que encuentran su origen... en circunstancias preexistentes cuya valoración jurídica no puede hacerse tan sólo a la luz de la letra de la ley».

La sentencia de Audiencia confirmada por el Tribunal Supremo en la de 13 de marzo de.1968, que dice: a... la facultad del artículo 172 de la Ley del Suelo, que es la invocada por el actor para imponer al Ayuntamiento la demolición que éste niega, ha de tener también, además de los límites que de su propio texto se infieren, los que la FUERZA DE LOS HECHOS, desde la solución que facilitan los principios en que se inspira aquel precepto, imponen... (porque)... pudo instarse su ejercicio cuando el edificio estaba en construcción y no una vez terminado...».

La sentencia del Tribunal Supremo de 3 de octubre de 1964 dice: «... si bien es cierto que la actividad de la Administración municipal en materia de licencias es reglada..., no lo es menos que se dan supuestos en que aquella debe considerar Ir OPORTUNIDAD de la concesión FRENTE a DETERMINADAS SITUACIONES OBSTATIVAS....

La de Audiencia confirmada por el Tribunal Supremo en la de 8 de mayo de 1972 dice: a... el problema litigioso queda determinado a concretar... si la voLUNTAD DEL AYUNTAMIENTo entrañaba, en el momento de la concesión de la licencia, unas condiciones urbanísticas que hayan sido vulneradas por el recurrente...».

La de Audiencia confirmada por la del Tribunal Supremo de 21 de marzo de 1972 dice: a...tal modificación supone, desde el punto de vista de la relación contractual entre el Ayuntamiento y la Empresa recurrente, esa inefectividad del CONVENIO O PACTO URBANISTICO celebrado entre ambos, que al ser unilateralmente realizada viene impedida por el artículo 1.256 del Código civil, y tal actuación administrativa municipal impulsa, de igual modo, contradecir los actos propios anteriores de la Corporación municipals.

Sobre cuyas bases resulta posible alcanzar conclusiones como las de las siguientes sentencias:

La del Tribunal Supremo de 17 de junio de 1961, que dice: «... no se aprecian fundamentos suficientes para justificar la sanción contra la que. se recurre en el mero hecho de haberse comenzado y realizado por los hoy actores la obra de que se trata, sin la correspondiente licencia municipals.

Y la sentencia de la Audiencia confirmada por la del Tribunal Supremo de 30 de mayo de 1972, que dice: a... estas dos plantas o áticos son clandestinos..., y motivó, sobre la base legal del ya citado artículo 172, el que el Ayuntamiento dictara el acuerdo impugnado, en el que POR PURA BENEVOLENCIA se legalizó un ático y se ordenó la demolición del otro, acuerdo que al igual que aquél procede confirmar, POR ESTAR AJUSTADO A DERECHO». 
«La Administración, buscando causar un menor perjuicio económico a los infractores y determinar repercusiones o consecuencias menos enojosas para el bien público, en relación con el problema de la vivienda que derivaría de la demolición de la construcción abusiva, opta por convalidar ésta, pero sin dejar de sancionar el abuso; conducta perfectamente correcta desde el punto de vista jurídico, cuando la vuelta al estado de hecho anterior a una infracción urbanística sea imposible o haya de originar consecuencias graves para los intereses generales o para los de particulares ajenos a la comisión de la infracción».

b) La limitación de las facultades revisoras que tiene la Jurisdicción contencioso-administrativa, y la limitación de la legitimación y de los tiempos para recurrir, serán una conquista de la praxis forense (?), que ayudará a consolidar infracciones urbanísticas, a pesar de que el interés público aconsejara lo contrario. Así, la sentencia del Tribunal Supremo de 21 de junio de 1965, que dice:

"Confirmación del fallo apelado, QUE HACE INNECESARIO EL ENJUICIAMIENTO SOBRE SI EXISTIO O NO ERROR EN EL ACUERDO MUNICIPAL QUE OTORGO LA LICENCIA, así como sobre la cuestión de si tal licencia se ajustó o no a las Ordenanzas entonces vigentes, o si el Ayuntamiento pudo tener o tuvo en cuenta otros acuerdos municipales POR NADIE IMPUGNADOS».

c) Frente a la prioritaria valoración del interés público, se llegará incluso a montar el parangón entre la libertad privada a edificar y el interés público. En sentencias como la del Tribunal Supremo de 24 de marzo de 1975, según la cual:

«... se define el grado en que el interés público se estima incompatible con la libertad de edificación..., razones que inducen a admitir la posibilidad de legalizar..., así como que la citada posibilidad de legalizar es asimismo DEBER JURIDICo...».

Si se tuviera que exponer la mejor aportación que esta corriente doctrinal ha dado a nuestro Derecho urbanístico, habría que encontrarla negativamente: si no se procura que el marco físico y

(3) La sentencia de Audiencia confirmada por la del Tribunal Supremo de 25 de febrero de 1974 dice: $\alpha . .$. o si se hizo no está demostrado en autos... y sin que en las declaraciones conste su aprobación en la forma definitiva... Carencia de prueba con que la Administración municipal desempeñó en el proceso cualquier posible punto de lucha que infiriese necesidad de condicionar la licencia». 
el marco social se vayan pareciendo al marco jurídico, todo intento de conseguir una disciplina urbanística no tendrá más valor que el dulce encanto de su ingenuidad, porque algunos grupos sociales siempre encontrarán el modo de forzar la aplicación de la norma, a fin de que ésta se acomode a sus intereses. Mientras no se controle el precio y el tráfico del suelo, es decir, mientras no se realice con profundidad una política de fiscalidad, será posible que se fuercen los preceptos legales-urbanísticos, dando una inflexión privada allí donde el frío precepto sólo marcaba una orientación pública.

El resultado será con frecuencia un edificio sin licencia, una parcelación de hecho, unas alturas de más. Resultado que será aplaudido por los usos sociales, que suelen recompensar a los que han triunfado en estos empeños. La recompensa y el éxito social estarán ahí. Y no conviene dar de lado a esta realidad, cuando se trata de valorar la infracción urbanística, si no se quiere caer en eufemismos: la causa de la infracción urbanística será frecuente verla concretada, y aún escamoteada, bajo el manto de actuaciones protegidas por el medio social - una benefactora y minúscula guardería en un edificio con plantas de exceso, una necesitada traída de aguas y creación de puestos de trabajo en una urbanización privada sin urbanizar, etc.-. En resumen, los valores de la sociedad arropan, con demasiada frecuencia, motivaciones privadas, causa sobre causa, las infracciones urbanísticas.

\section{ENFOQUES PUBLICISTAS}

Frente a los anteriores planteamientos, nuestra legislación urbanística, la del 56 y más aún la del 75 , acentúan el aspecto público de todas las conductas urbanísticas. El urbanismo es entendido como una auténtica función social, y la fiscalización urbanística se asienta en dos principios esenciales y en dos principios subsidiarios. 
REVL-1977, núm. 195. BOIX REIG, VICENTE. UN MARCO PARA EL ESTUDIO DE LA INFRACCI...

UN MARCO PARA EL ESTUDIO DE LA INPRACCION URBANISTICA

A) Principios esenciales

a) Principio de la legalidad urbanística

La ley, en cualquiera de sus variadas formulaciones urbanísticas, ha de acatarse en cualquier tipo de decisión que se tome para el uso del suelo o de la edificación. Teniendo los demás valores y fuentes jurídicas, la tarea de complementar e interpretar la ley. Hay en este sentido una importante y sobre todo reciente línea jurisprudencial (4), en la que se encuentra la sentencia del Tribunal Supremo de 23 de abril de 1975, que establece:

a... el primer principio a tenerse en cuenta es el de la legalidad, no pudiéndose olvidar o haber igualdad sin legalidad... Para que el principio aducido -el de la igualdad - tenga operatividad, se necesita que la legalidad vigente permita lo edificado, pues del hecho de que varias veces se hubiera conculcado la legalidad vigente, no puede racionalmente inferirse que tenga que seguirse conculcando la legalidad, PUES ENTRE LA FRICCION DE AMBOS PRINCIPIOS, ES EL DE LA LEGALIDAD EL QUE HA DE PRIVAR».

(4) La sentencia de Audiencia confirmada por la del Tribunal Supremo de 3 de enero de 1975 dice: $\alpha . .$. es de orden reglado, no pudiendo, en consecuencia, el Ayuntamiento, por su libre voluntad, acordar lo que tenga por convenienten.

Y con esta doctrina es posible ultimar razonamientos como el de la sentencia del Tribunal Supremo de 25 de junio de 1973, que dice: a... ninguna interpretación restrictiva ni extensiva debe ser hecha de tal potestad, sino que, por el contrario, debe ser entendida de modo que naturalmente sirva con eficacia a los intereses generales en cuya protección se concede sin lesionar, en efecto, los legítimos de los particulares, pero sólo en tanto éstos sean VERDADERAMENTE LEGITIMOS, Y NO LO SON CUANDO CONTRADICEN ABIERTAMENTE, como en este caso ocurre, las Ordenanzas, de una parte, y de otra los términos precisos y claros de una licencia que al lado de una permisión contiene una prohibición expresa que ha sido violada».

Y se plantea incluso el problema de la realidad hipotecaria cuando la sentencia de Audiencia confirmada por la del Tribunal Supremo de 7 de junio de 1972 dice: «... que sin desconocer el carácter reglado de la actuación administrativa municipal... la protección que al particular inscrito otorga el artículo 38 de la Ley Hipotecaria y el conjunto de facultades que el Código civil reconoce al propietario en sus artículos $348 \ldots$, no son tan omnímodas que puedan desarrollar al margen de las regulaciones administrativas, que en áreas predominantemente influidas por el interés público, pautan su ejercicio, como ocurre con el artículo 165 de la Ley del Suelo y artículos $1 . .$. del Reglamento de Servicios, por ello cuando LA ADMINISTRACION MUNICIPAL SE ENCUENTRA CON TITULACIONES DE DOMINIO QUE SE HALLEN EN OPOSICION CON REALIDADES EXTRARREGISTRALES Y DE HECHO, que rompen el sistema de coordinación y SUBORDINACION DE LOS DERECH OS DEL PARTICULAR CON LOS INTERESES PUBLICOS DERIVADOS DE TALES SITUACIONES manifiestas, ostensibles y muy calificadas, aunque éstas no gocen de una protección formal, ha de estimarse autorizada aquélla para decidir acerca de la oportunidad de conceder la licencia que se le solicite, y por su consecuencia la de denegarlax. 
Sobre esta línea de pensamiento, queda reducida a sus justos términos cualquier alegación sobre la vigencia del principio de igualdad de los administrados. Como en la sentencia de 26 de febrero de 1970, que dice:

«Que el principio de igualdad de los administrados ante la actuación administrativa -artículo 2 del Reglamento de Servicios y artículo 3 del Fuero de los Españoles- no debe entenderse en el sentido que postula el recurrente, pues precisamente por tratarse de una igualdad "ante la ley", no puede sustentarse en situaciones manifiestamente ilegales...».

\section{b) Principio de la congruencia urbanística}

Habrá que tener en cuenta, en segundo término, un criterio de moderación en la interpretación de los esquemas legales, a fin de atemperarlos a la variedad de supuestos que plantea el cambiante hacer urbanístico en cualquier medio social dinámico. No se trata de elevar la regla de la oportunidad o conveniencia a un plano de confrontación con la regla de legalidad. Se trata de interpretar el conjunto normativo de una manera armónica con la exigencia social, entendiendo por ésta la que siente toda la comunidad y no sus estamentos privilegiados. Esta armonía en la interpretación bien podemos encauzarla a través del que calificamos principio de congruencia urbanística, que expresamente se recoge en algunas recientes sentencias (5), tales como la de 17 de enero de 1975 , que dice:

a... existencia de actos sancionadores del nuevo plan, por incompleto que éste fuera en algunos extremos, lo que impedía autorizar obras que habían de pugnar con el mismo, cualquiera que fuera la fecha de aprobación de todos y cada uno de sus elementos, incurriendo en INCONGRUENCIA URBANISTICA atentatoria a los intereses públicos de las planificaciones, que priman sobre los particulares».

(5) Y la del Tribunal Supremo de 6 de mayo de 1975, que dice: -Resulta inconcuso que conforme al PRINCIPIO DE CONGRUENCIA URBANISTiICA de los artículos 1 , $4,5,6,9$ y 15 del Reglamento de Servicios, el Ayuntamiento se ajustó... a lo que constituía, no ya una indicación de policía urbanística, sino obligación derivada del sistema de planeamiento». 


\section{B) Principios subsidiarios}

a) Principio de la interpretación discrecional

Sin que se confunda lo discrecional con lo arbitrario, sí parece conveniente apuntar la existencia de competencias administrativas discrecionales, para interpretar el ajuste a derecho de supuestos de hecho que por su singularidad no tienen encuadre exacto en la norma positiva. Con supeditación en todo caso a los dos principios anteriores, y como natural consecuencia del principio de la congruencia urbanística, es posible aplicar criterios discrecionales dentro de la esfera de actuación contemplada, entre otras, en la sentencia del Tribunal Supremo de 21 de marzo de 1972, que confirma la de Audiencia, que dice:

«... no se alega criterio legal o reglamentario, ni siquiera normas de Ordenanzas que suministren apoyo para la adopción del mencionado criterio de medición..., sin que sea válida la alusión genérica al criterio municipal que se viene aplicando, pues habría de acreditarse, además, que es el mismo seguido en otros supuestos similares al presente... Nos encontramos ante materia que en ausencia de norma expresa que confiera a la actividad administrativa un neto carácter reglado, ha de ser valorada por el Ayuntamiento con un CIERTO MARGEN DE APRECIACION DISCRECIONAL.... .

b) Principio de la variabilidad urbanística

La dinámica social puede imprimir un importante ritmo de cambio a la norma urbanística. Puede por ello suceder que los elementos de juicio utilizados en un momento dado para dictar determinado acto administrativo varien con el tiempo, de manera que tal que en una época posterior, un fenómeno similar sea susceptible de una decisión administrativa diferente. Es por ello por lo que en materia urbanística no tiene especial consistencia la doctrina de la cosa juzgada o del acto administrativo firme, pues aun siendo válidas estas instituciones, la variabilidad urbanística limita de hecho el marco de su utilización en su esfera. En esta línea es abundante y uniforme la línea jurisprudencial (6), seña-

(6) Y la sentencia de Audiencia confirmada por la del Tribunal Supremo de 
lada entre otras en la sentencia del Tribunal Supremo de 22 de junio de 1962, que dice:

a... sin olvidar que las circunstancias del urbanismo no son ni pueden ser de naturaleza estática o permanente, sino que necesariamente cambian y evolucionan con el transcurso del tiempo y con los demás motivos generales y locales de desarrollo de las poblaciones interesadas".

\section{EL CONTENIDO DE LA INFRACCION URBANISTICA}

El contenido de la infracción urbanística se puede examinar mediante el estudio de los valores jurídicos que el Derecho urbanístico entiende que debe defender, o mediante el estudio de los daños sociales que produce la vulneración de esos valores jurídicos. Vamos a utilizar ahora el primero de los enfoques, que parece más útil para retratar el marco en el que puede surgir el ilícito, aunque esta no sea la óptica ordinaria del legislador.

\section{LOS BIENES JURfDICO-URBANISTICOS Y SU DEFENSA}

Puede afirmarse que el urbanismo en su moderna dimensión influye en buena parte de las parcelas de la convivencia humana, que ha quedado irremisiblemente condicionada por este fenómeno. Nuestra Ley del Suelo intenta canalizarlo, y su artículo 3 establece el cuadro de tareas urbanísticas.

El examen de ese cuadro de tareas es el que nos introduce en la comprensión de cuáles son los bienes jurídico-urbanísticos que a juicio del legislador deben ser protegidos. Valga una remisión en bloque a este auténtico cuadro de principios programáticos, que ofrece los siguientes rasgos peculiares:

a) Se observa una yuxtaposición de criterios socializantes montados sobre una base capitalista. De la conjunción de idearios opuestos resultará en el texto más de una institución deficiente, y por ello propensa a su vulneración.

28 de abril de 1972, que dice: aLa naturaleza singular de estos actos administrativos que son las licencias, hace que sean siempre reiterables las peticiones a ellas referidas...». 
b) A esta extraña amalgama habrá que sumar la misma dimensión gigantesca del urbanismo moderno. La variedad de matices que caracteriza a sus instituciones precisará de estudios pluridisciplinarios y de coordinadas actuaciones cuando se deban tomar medidas represivas.

c) La amplitud de los bienes jurídico-urbanísticos determinará que en un mismo fenómeno concreto sea posible la concurrencia de una amplia gama de bienes jurídicos a defender.

Estas características peculiares de los bienes jurídico-urbanísticos lleva consigo una especial dinámica en la tensión entre derecho objetivo y derecho subjetivo urbanísticos.

\section{EL DERECHO OBJETIVO Y EL DERECHO SUBJETIVO URBANISTICOS}

El orden jurídico-urbanístico se constituye con bienes jurídicos de distinto orden: predomina en unos el interés público, y el privado en otros; pero con tal interacción de valores, que no es posible apartar del conocimiento jurídico-público los deterioros de ninguna parcela de la materia jurídico-urbanística. Y resulta entonces natural:

a) Que la competencia administrativa debe alcanzar de alguna manera a todos los fenómenos y a todos los sujetos urbanísticos. Así sucede teóricamente en el artículo 3 de la Ley. Pero en la praxis de esta misma Ley serán detectables fisuras en los ámbitos de competencias público-urbanísticas.

b) Que la legitimación del particular supere los supuestos ordinarios contemplados por el artículo 28 de la Ley de lo Contencioso-administrativo y alcance la amplitud de la acción popular prevista en el artículo 235 de la Ley del Suelo. Aunque la práctica limite de hecho la capacidad operativa de esta acción popular.

c) Que la atribución de competencias a los diversos organismos y órganos de la Administración admita variados supuestos de transferencia coactiva de competencias administrativas, como las que enunciativamente se contemplan en los artículos 188, 3 , 217,2 y 218 de la Ley del Suelo. Montaje que, sin embargo, no es 
diáfano, por la práctica influencia prepotente de unos órganos administrativos frente a otros, que limita la validez de los deslindes interorgánicos de competencias.

En todo caso, la vulneración de un bien jurídico-urbanístico pondrá en marcha los resortes legales previstos, tanto en defensa de los derechos objetivos como de los subjetivos lesionados. Hay en esta materia una regla general de Derecho: cuando se vulnera un derecho objetivo, la norma legal previene una actuación de tipo represivo (mientras que cuando se infringe un derecho subjetivo, lo que busca la norma es restaurarlo). Pues bien, este montaje no parece válido en Derecho urbanístico: al existir siempre daños individualizables cuando se produce un desorden urbanístico (patrimonio público de la Administración, patrimonio privado de la Administración o patrimonio particular), será siempre necesario e imprescindible, para reponer el orden jurídico, restaurarlos. En la restauración, y esto conviene subrayarlo, se encuentra la sustancia del tratamiento de la infracción urbanística; las medidas represivas quedarán como un uso complementario, accidental, cuyo uso dentro de ciertos límites, que estudiaremos en otra ocasión, estará guiado por criterios discrecionales.

\section{BIEN JURfDICO-URBANISTICO E INSTITUCIONES URBANISTICAS}

Los bienes jurídicos descritos en el artículo 3 de la Ley del Suelo deben materializarse en las diversas figuras y supuestos jurídicos contemplados en el articulado del propio texto legal, pues de otro modo la indicada descripción quedaría reducida a una declaración utópica de principios programáticos. Pero la Ley del Suelo no contempla a todas las instituciones que precisa la fenomenología del urbanismo moderno; siendo incluso discutible que el tratamiento legal de todas y cada una de las instituciones resuelva con profundidad las necesidades que plantea el respectivo problema urbanístico. Esta deficiente regulación se viene a corresponder con índices elevados de indisciplina urbanística.

Es por ello conveniente resaltar las instituciones urbanísticas principales, inspiradoras del complejo de figuras e instrumentos de la Ley del Suelo, para poder contrastar en todo momento tanto la operatividad de tales figuras e instrumentos, como su suficiencia. 
Sin intención exhaustiva, se pueden señalar como principales instituciones urbanísticas las siguientes:

- La propiedad urbanística. Los derechos y obligaciones del dominio privado se transforman en un conjunto de facultades y cargas, en las que confluyen junto a los intereses privados intereses públicos de especial relevancia.

- La planificación urbanística. Norma jurídica definidora de la propiedad urbanística y canalizadora del desarrollo urbanístico.

- La información urbanística. Nexo de participación del particular en la realidad del planeamiento.

- La reparcelación. Operación macrourbanística de convertibilidad de unas facultades y cargas individuales en otras, por razones de interés colectivo.

- La unidad urbanística. Elemento físico para la actuación urbanística indivisible en el nivel operacional de que se trate. Tras la parcela y el polígono, los instrumentos inmobiliarios.

- Legalidad urbanística. Conjunto de normas de diverso rango, de obligatorio cumplimiento para la Administración y para los administrados.

- Gestión urbanística. Complemento de técnicas, que apoyan el compromiso de creación de infraestructura y dotación de los equipamientos planificados, que asume una entidad pública, privada o mixta.

- Disciplina urbanística. Situación de orden jurídico-urbanístico, cuya conservación asume la Administración pública del urbanismo.

La modulación que se dé a estas instituciones y el énfasis que se haga en los intereses públicos o en los privados, así como la adopción de un criterio similar en la articulación de las diversas instituciones, es lo que dota de valor unitario a un cuerpo legal. El que nuestra Ley del Suelo lo haya o no conseguido, y el que ese cuerpo unitario sea un feliz reflejo de la exigencia social, es algo que en buena medida se infiere del estudio de las concretas infracciones urbanísticas. 


\section{UN METODO PARA EL ESTUDIO DE LA INFRACCION URBANISTICA}

La Ley del Suelo regula ciertas instituciones, procurando que su eficacia mejore la armonía social. Y para asegurar este deseo, el legislador apoya a estas figuras jurídicas con ciertas técnicas de represión, cuya utilización limita a aquellas situaciones incontroladas o de desorden social.

Parece posible apuntar que las instituciones urbanísticas se sitúan en el plano creador y constructivo de la norma legal y constituyen la concreta respuesta del legislador a la exigencia social que plantea el fenómeno urbanístico; mientras que, por su parte, las técnicas represivas sólo son utilizadas por el Derecho positivo para resolver aquellas situaciones extremas, anormales, que se escapan del cauce general y ordinario.

\section{INSTITUCIONES URBANISTICAS Y TECNICAS REPRESIVAS}

Si se desea formular un juicio sobre la validez de las instituciones urbanísticas, es decir, si se estudia la relación entre las normas institucionales, las normas represivas y la realidad social, resultará posible clasificar a las instituciones urbanísticas en los siguientes grupos:

a) Instituciones que sí son capaces de encauzar ordenadamente el real fenómeno urbanístico.

b) Instituciones que previenen una utilización frecuente de técnicas represivas, lo que puede encerrar su propia incapacidad para canalizar debidamente el propio fenómeno.

c) Instituciones que olvidando el fundamento excepcional de las medidas coactivas, las confunde, mixtifica y amalgama, con su propia estructura, lo que puede llevar a que se conviertan en simples instrumentos de opresión social.

En resumen, pues, podrá haber instituciones válidas, podremos encontrarnos con instituciones deficientes, y será incluso posible detectar en el mundo urbanístico instituciones realmente adulteradas. 
Pero, ¿cuál es la posición de nuestro legislador? ¿Considera que la disciplina urbanística se consigue con el normal juego de sus instituciones, o entiende imprescindible apoyar la influencia social y la eficacia de éstas con técnicas represivas?

\section{MÉTOdOS PARA EL ESTUdIO DE LAS INSTITUCIONES URBANISTICAS}

Se pueden estudiar estas cuestiones partiendo de alguno de los siguientes esquemas metodológicos:

\section{A) Método dogmático}

Una formulación clásica somete a tela de juicio el contenido material de la institución urbanística que estudia: se definen los fenómenos y las exigencias sociales, y se declara la justicia o injusticia de la norma, según responda o no a tal necesidad social; pero quizá se preste poca atención a la influencia de los elementos y de los factores fenomenológicos que operan en la coyuntura histórica de que se trate.

Es curioso que precisamente con palancas de tipo dogmático se intenta en ocasiones justificar actuaciones urbanísticas torcidas. En nuestro urbanismo histórico y en el actual se puede rastrear más de un ejemplo. Nos remitimos ahora a los comentarios incorporados, a los que hemos llamado «enfoques privatistas» de la causa del ilícito urbanístico.

Pero formulaciones de este corte, con frecuencia sirven más a planteamientos legitimistas que a construcciones perfeccionadoras del orden jurídico-urbanístico, ya que en todo caso sus conclusiones suelen ser poco sensibles a la concreta necesidad urbanística de cada día.

Parece más conveniente que busquemos otro esquema, una más modesta meta que sustituya las formulaciones dogmáticas por otras más pragmáticas. Y sólo detrás de éstas, aunque con su apoyo, podrá ser viable intentar alguna modesta y condicionada conclusión dogmática. 


\section{B) Método analítico}

a) Idea general

Esta formulación se plantea en estudio experimental de las concretas instituciones jurídico-urbanísticas, observando su nivel de acoplamiento y de ensamblaje con los entramados orgánicos y con los fenómenos reales, y paralelamente observando el nivel de utilización de las técnicas represivas montadas por la ley para apoyar la eficacia de la correspondiente institución. En aquellos supuestos en los que el examen lleve a una conclusión negativa sobre una institución concreta, se buscará una explicación a la insuficiencia, se intentará comprender la necesidad que tuvo el legislador de potenciar el juego de técnicas represivas, y se analizarán medios viables para sustituir el aparato punitivo a base de mejorar el aparato institucional.

Este método parece más eficaz para buscar causas, incorporar elementos y trabajar en el perfeccionamiento de instituciones urbanísticas. Este método es, por tanto, una toma de posición del estudioso que se enfrenta ante esa realidad social que es la indisciplina urbanística.

\section{b) Caracteres}

Este método de análisis parece además imprescindible en un Derecho tan contingente, variable y dinámico, como es el administrativo, y es de plena aplicación en un Derecho como el urbanístico, en el que resulta necesario y a la vez difícil alcanzar la trabazón con el dinámico fenómeno que regula.

Necesario, porque el fenómeno urbano tiene una tal dimensión que se está convirtiendo en uno de los más importantes y decisivos para la vida de cualquier comunidad humana, hasta tal punto que su interpretación y su canalización en normas jurídicopositivas es un reto que ninguna esfera de poder público puede soslayar.

Es al mismo tiempo difícil, porque esa misma dimension multiplica los factores variables del fenómeno, complicando y diversificando sus interdependencias. Los problemas urbanisticos son 
en ocasiones fáciles de detectar, porque se encuentran en la superficie de la convivencia urbana; pero en todo caso suscita especial dificultad definirlos con claridad. Al enmarañarse los lindes de la realidad urbanística, resulta enrevesado definir el marco de actuación de sus instituciones, y más aún dar a las mismas unas formas jurídicas adecuadas. Como consecuencia, el Derecho positivo ofrece unos marcos institucionales siempre insatisfactorios. Esta permanente insuficiencia da el acento creador al enfoque del investigador.

\section{c) Límites}

Y como consecuencia, el método analítico, si bien profundiza, reduce los espacios de su estudio, ya que se adentra todo en aspectos concretos del fenómeno urbanístico. Y también como consecuencia de especial relieve una importante limitación en el tiempo: el dinamismo del fenómeno urbano convierte en renovables y variables cualesquiera estudios que se acometan sobre el mismo. Las conclusiones y las medidas que el investigador pueda proponer para la mejora de las instituciones urbanísticas tendrán, pues, una relatividad sustancial.

\section{CONCLUSIONES}

Nuestra legislación urbanística disfruta, en líneas generales, de una estimable calidad técnica; con frecuencia nuevos textos reglamentarios, también de calidad, enriquecen el patrimonio legislativo. Paradojicamente, sin embargo, el desorden urbanístico aumenta por doquier. Y quizá por ello se siguen invirtiendo importantes caudales de energía en fabricar más reglamentos, más planes de urbanismo, más normas complementarias; nuestro barroquismo iusurbanístico continúa superándose, montando más controles para la inalcanzada legalidad de la licencia de obras. Y el desorden sigue creciendo.

No parece que esté de más señalar que todos estos esfuerzos legales, jurisprudenciales, doctrinales y administrativos, debieran merecer una notable mejora en el orden urbanístico del país; pero que en buena parte estos esfuerzos serán vanos mientras los pre- 
supuestos y los medios sociales en los que se desarrolla el fenómeno y la indisciplina urbanística no sean tratados con profundidad por el poder público. Por esta vía, el Derecho urbanístico y el método para su estudio se conectan irremediablemente con la temática propia de la sociología política. Buenos serán estudios urbanísticos en el marco de esta nueva ciencia, si no deseamos hacer del urbanismo y del Derecho urbanístico un gran eufemismo. 